\title{
Towards a TPACK-fostering ICT instructional process for teachers: Lessons from the implementation of interactive whiteboard instruction
}

\author{
Joyce Hwee Ling Koh and Shanti Divaharan \\ National Institute of Education, Nanyang Technological University, Singapore
}

\begin{abstract}
This paper describes an on-going design-based research project that aims to develop an instructional process to facilitate pre-service teachers' technological pedagogical content knowledge (TPACK) development as they learn to integrate information and communication technology (ICT) in their teaching content subjects. In conjunction with an initiative to prepare pre-service teachers for integrating interactive whiteboard (IWB) in their teaching subjects, an instructional process comprising of tutor modelling, hands-on exploration, and group-based design was implemented. The data collected during this first implementation cycle (Cycle 1) was used to enhance the second implementation cycle (Cycle 2) through the inclusion of classroom-based case studies, subject-based design ideas and opportunities for peer sharing. The findings from both implementation cycles reveal that strategies such as tutor modelling and hands-on exploration of ICT tools appeared to be more advantageous for fostering technological knowledge and technological pedagogical knowledge. Group-based design experiences supported the pre-service teachers to formulate TPACK. The paper concludes with a discussion about the future developments of these TPACK-fostering ICT instructional processes.
\end{abstract}

\section{Introduction}

Technological pedagogical content knowledge (TPACK) is a theoretical construct formulated by Mishra and Koehler (2006) to characterize teacher knowledge with respect to the integration of information and communication technology (ICT) into teaching and learning activities. According to Mishra and Koehler, this body of knowledge is derived from the connections that teachers make between their technological knowledge (TK), pedagogical knowledge (PK), and content knowledge (CK). However, Mishra and Koehler's conception of TPACK describes the sources of knowledge underlying technology integration expertise but not how these can be fostered, which is recognized as a gap in TPACK research (Cox \& Graham, 2009). Particularly, the instructional processes that foster teachers' knowledge for ICT integration are generally lacking (Brush \& Saye, 2009), more so their corresponding influences on teachers' TPACK development.

This paper describes the on-going efforts to design an instructional process that supports pre-service teachers' TPACK development as they learn to use ICT tools in educational technology courses (see Koh \& Divaharan, 2011). In conjunction with an initiative to prepare pre-service teachers for using the interactive whiteboard (IWB) in Singapore schools, the instructional process first developed in Koh and Divaharan was tested with a group of 50 pre-service teachers. Content analysis was carried out on the preservice teachers' pre and post intervention learning reflections to understand their TPACK development throughout the instructional process. This was the Cycle 1 of the design-based research. The findings from this cycle informed the refinements to the instructional process. The instructional approach was then modified and similarly evaluated during the second implementation cycle (Cycle 2) with 48 pre-service teachers. The paper presents the development of pre-service teachers' TPACK with respect to the refinements made to the IWB instructional process in both the implementation cycles. The implications of the findings to the development of a TPACK-fostering ICT instructional process will be further expounded.

\section{Literature review}

\section{The TPACK framework}

Shulman (1986) termed teaching expertise as pedagogical content knowledge (PCK), theorizing that it is derived from the integration of teachers' pedagogical knowledge and content knowledge. Mishra and 
Koehler (2006) proposed that when technological knowledge (TK) is added to Shulman's conception of PCK, the notion of technological pedagogical content knowledge (TPACK) can similarly be used as a theoretical lens for understanding teachers' technology integration expertise. Their seven-construct TPACK framework outlines the knowledge of technology tools (technological knowledge, TK), knowledge of teaching methods (pedagogical knowledge, PK), and knowledge of subject matter (content knowledge, CK) as the three main sources of teachers' technology integration expertise. The four other types of knowledge include Shulman's PCK, which was incorporated into this framework as teachers' knowledge about teaching methods with respect to subject matter content (pedagogical content knowledge, PCK). Teachers also connect TK with PK and CK to define their knowledge of using technology to implement different teaching methods (technological pedagogical knowledge, TPK), and their knowledge of subject matter representation with technology (technological content knowledge, TCK). Besides making connections between two sources of knowledge, teachers can also combine TK, $\mathrm{PK}$ and $\mathrm{CK}$ to formulate knowledge for using technology to implement teaching methods for different subject matter content (technological pedagogical content knowledge, TPACK).

The TPACK framework generated much interest among teacher educators which culminated in the publication of a handbook describing how TPACK can be characterized in subject areas such as English, Social Studies, Mathematics, and Science (see AACTE, 2008). In some subject areas, the seven TPACK constructs theorized by Mishra and Koehler (2006) served as a theoretical basis for formalizing the body of knowledge to be imparted through technology integration curricula (Grandgenett, 2008; McCrory, 2008). In others, the TPACK constructs were used to analyse the types of knowledge that teachers develop during technology integration and ICT courses (see Hughes \& Scharber, 2008; Özgün-Koca, Meagher, \& Edwards, 2009/2010). These studies show that the TPACK framework has contributed a theoretical lens for describing teachers' ICT integration knowledge in various subject disciplines. Such kinds of knowledge have traditionally been hard to define. Nevertheless, as noted by Cox and Graham (2009), the framework still needs to be further developed in aspects pointing to how teachers acquire TPACK. Teacher educators have reported successful methodologies for instructing pre-service teachers about ICT integration practices even before the conceptualization of TPACK (e.g. Brush et al., 2003). Their influences on teachers' TPACK, if examined thoroughly, can potentially enrich the practical use of the TPACK framework towards teacher ICT development. Nevertheless, after the conception of TPACK, much attention has been given to the need for teacher participation in ICT design activities (see Koehler \& Mishra, 2005a) which could limit the range of instructional approaches considered for TPACKfostering ICT instruction in teacher education. Therefore, it is necessary to examine how previously successful ICT instructional approaches could contribute to fostering teachers' TPACK.

\section{TPACK- fostering instructional processes}

Teacher educators have been exploring various ways to instruct teachers about ICT integration practices even before the conceptualization of TPACK. Before the conception of TPACK, a considerable number of studies have discussed programme-wide strategies to strengthen teachers' confidence in ICT integration. These studies largely concluded the need for teacher education curricula to provide pervasive faculty modelling of technology integration practices, hands-on ICT lesson design activities, and ICT field-based practicum (Brush, et al., 2003; Handler, 1993; Strudler \& Wetzel, 1999). The TPACK framework extends these studies because it suggests a theoretical basis for teacher educators to measure the outcomes of ICT courses, which, in earlier studies were largely centred upon building teachers' confidence for ICT integration. Therefore, exploring the impact of ICT course instructional approaches on teachers' TPACK formation is pertinent.

Koehler and Mishra (2005b) argued that teachers' TPACK development is best fostered in ICT learning environments that provide them with opportunities to apply their technological knowledge, pedagogical knowledge and content knowledge in an integrated manner. Teacher involvement in the design of ICTintegrated lessons is one example of a TPACK-fostering instructional strategy because it engages teachers in the resolution of authentic problems related to ICT integration through lesson design. Studies by Koehler, Mishra, and Yahya (2007), and Koehler and Mishra (2005a) support this postulation. Content analysis of groups working on ICT design projects revealed that their engagement with the project problem throughout the course semester resulted in an increase of their discussions about issues associated with TPK, TCK, and TPACK. By contrast, their discussions at the beginning of the semester showed them considering TK, PK, and CK in isolation. Angeli and Valanides (2009) rated teacher's 
TPACK on their ability to apply the appropriate ICT tools for the teaching of subject matter that are difficult to teach with traditional means. Their study also found that teacher engagement in multiple design tasks throughout an ICT course improved the TPACK score awarded to their ICT design projects.

By far, ICT design projects appear efficacious for fostering teachers' TPACK. Nevertheless, Koh and Divaharan (2011) cautioned against ignoring the instructional strategies that were proven successful for enhancing teachers' confidence for ICT integration. Studies of teachers' TPACK development process found that they needed to build acceptance and confidence of using an unfamiliar ICT tool before they were able to explore its pedagogical uses (Niess, 2007). Angeli and Valanides' (2009) ICT course for 215 pre-service teachers adopted an instructional process that incorporated faculty modelling of subject-based ICT integration examples and teacher practice of ICT tools before individual design work were assigned. This shows that some form of pre-design activities may be needed to prepare teachers for their design projects. Such activities could be important for providing teachers with aspects of TPK, TCK, and PCK that can be applied to their design problem. Such kinds of instructional scaffolding may better equip teachers to foster TPACK through their design experiences.

Brush and Saye (2009) observed that prescriptions of instructional processes that develop teachers' ICT integration expertise in educational technology or methods courses are generally lacking. TPACK studies such as Koehler and Mishra (2005a) and Koehler and Mishra (2005b) have focused on examining the efficacy of using design projects in ICT courses. However, details about the general instructional processes used in their courses are lacking. Such information might provide readers with a comprehensive picture about the instructional processes that support teachers' TPACK development. The applicability of TPACK as a theoretical framework for planning ICT courses can be greatly enhanced through further studies about TPACK-fostering instructional processes.

\section{Research question}

Given the above analysis, the following research question will be examined in this study: What are the characteristics of an instructional process that fosters pre-service teachers' TPACK development during ICT courses?

\section{Methodology}

\section{Study context}

Design-based research is an approach that aims produce or improve practices and have an impact on teaching and learning in naturalistic settings (Cobb, diSessa, Lehrer, \& Schauble, 2003). This study adopted a design-based research approach because the intent was to study and refine a TPACK-fostering ICT instructional process as the process was being applied. Knowledge and understanding about instructional processes can also be built through design-based research as Brown (1992) asserted that this methodology allows for significant variables and relationships to be discovered in the naturalistic environment of classrooms. Lesh, Kelly, and Yoon (2008) proposed that through iterative cycles, such kinds of knowledge and understanding can contribute to "theory-building" about instructional processes in the long-run. It was conducted with Singapore pre-service teachers who attended a 12-week core ICT course during their teacher education programme. The first five weeks of this course equips them with relevant theories and principles for effective ICT integration. The subsequent seven weeks of the course provides them with opportunities to explore the pedagogical uses of ICT tools through specialized technology enabled lessons (TELs) featuring tools such as concept mapping, digital games, webquests, and Web 2.0 tools such as wikis and blogs. Students in these tutorial groups were organised according to teaching subject specialization. Each tutorial group selected two or three TELs that were relevant to their teaching subject for in-depth exploration during the seven weeks of the course in consultation with their tutor. Each TEL unit is designed to last either two or three tutorial sessions and each weekly tutorial session lasts two hours. A typical TEL instructional process starts with tutor modelling, following which pre-service teachers practice the technical functions of the ICT tool. This is followed by exploration of lesson samples, and finally they work in project teams to design ICT integrated lessons using the tool that they learnt during the TEL segment. 
During the July 2009 semester, a new three-week TEL on the IWB, developed by the second author, was introduced into the curriculum. This IWB TEL comprises three two-hour lessons. Since the types of instructional strategies that foster TPACK during ICT instruction have not been clearly articulated in the current research studies, the authors sought to investigate how the TEL process fostered TPACK during this first implementation cycle (Cycle 1) by drawing upon the lessons from an exploratory study that was completed earlier (see Koh \& Divaharan, 2011). The results from Cycle 1 informed the refinement of the instructional process for Cycle 2, which was carried out the following year. Each implementation cycle was approached as a design-based research cycle to better understand how ICT instructional processes fostered TPACK. When discussing the findings for each cycle, we highlighted the lessons learnt and their implications for improving the instructional process.

\section{Study participants}

Since the pre-service teachers worked in project teams to explore the IWB and design their IWBintegrated lesson, each project team was considered as a unit of analysis. Cycle 1 was conducted with 12 project teams (50 pre-service teachers) who were enrolled in the post-graduate diploma in education (PGDE) programme at a teacher-training institute in Singapore. They were being trained to teach curriculum subjects for Mathematics, Chemistry, History, and English language in Singapore secondary schools. To ensure similarity of study participants' profile to Cycle 1, 11 project teams (48 pre-service teachers) enrolled in the same PGDE programme were selected for Cycle 2 that was conducted during the July semester of the following year. The Cycle 2 participants were also being trained to teach curriculum subjects such as Mathematics, Physics, English language and History in Singapore secondary schools. Similar to the pre-service teacher participants in Cycle 1, the Cycle 2 participants were from two tutorial groups taught by the second author who chose the IWB for in-depth exploration during TEL. In both cycles, data was collected during Weeks 6 to 8 of the semester where the IWB TEL was being conducted.

\section{Data collection}

Existing TPACK studies have found that teachers' TPACK development was best examined through content analysis of their project team discussions as they designed ICT-integrated lessons (Angeli \& Valanides, 2009; Koehler \& Mishra, 2005a; So \& Kim, 2009). Following this precedent, qualitative data about the TPACK development of each project team were captured through their group reflections submitted at the end of the first IWB TEL session and at the end of the semester. The reflections at the end of the first session were used to examine the efficacy of the instructional strategies (e.g., tutor modelling, review of self-paced learning materials and hands-on exploration) that were used to prepare the pre-service teachers to embark upon their IWB lesson design. Each project team submitted a consolidated reflection on the class discussion board with respect to the following questions:

1. What features about the IWB did you learn?

2. How can the features be used to support your teaching/ students' learning?

At the end of the semester, each project team submitted a document stating their rationalization for using the IWB in an ICT-integrated lesson they had designed. Both the reflections and the rationalization documents were coded qualitatively to examine teachers' TPACK development with respect to the integration of the IWB throughout the TEL.

\section{Data analysis}

The data from group reflections and the rationalization document were analysed through content analysis. The findings informed the answers to the research questions. The documents submitted by each project team were first classified into distinct ideas related to IWB use. Each idea was then coded with the seven TPACK categories as defined by Mishra and Koehler (2006). The authors first coded all the ideas independently. They then resolved discrepancies until there was perfect agreement. The coding protocol (see Table 1) shows that five out of the seven TPACK categories emerged from the analysis of preservice teachers' reflection comments. The research question was answered through analysis of the relative percentages of each TPACK category and also through qualitative evaluation of the reflections. 
Table 1

TPACK coding categories

\begin{tabular}{|c|c|}
\hline TPACK construct & Coding Example \\
\hline $\begin{array}{l}\text { Pedagogical Content Knowledge }(\mathrm{PCK})- \\
\text { knowledge of learning strategies to address } \\
\text { difficulties that students face when learning subject } \\
\text { matter }\end{array}$ & $\begin{array}{l}\text { When taught using conventional teaching tools, } \\
\text { algebra in general is viewed as a "dry" topic } \\
\text { comprising of only mechanical workings and } \\
\text { unrealistic problems. }\end{array}$ \\
\hline $\begin{array}{l}\text { Technology Knowledge (TK)- features and } \\
\text { functions of the Interactive Whiteboard }\end{array}$ & $\begin{array}{l}\text { We learnt how to do video playback, using pen tools, } \\
\text { eraser, protractor, compass, ruler, making multiple } \\
\text { choice quiz. }\end{array}$ \\
\hline $\begin{array}{l}\text { Technological Content Knowledge (TCK) - } \\
\text { knowledge of subject matter representation with } \\
\text { the Interactive Whiteboard. }\end{array}$ & $\begin{array}{l}\text { The protractor, compass and ruler tools can be } \\
\text { incorporated into our teaching of geometry. }\end{array}$ \\
\hline $\begin{array}{l}\text { Technological Pedagogical Knowledge (TPK)- } \\
\text { knowledge of implementing different teaching } \\
\text { methods with the Interactive Whiteboard }\end{array}$ & $\begin{array}{l}\text { The IWB allows students with short attention spans } \\
\text { to learn better by being interactive and capturing their } \\
\text { attention while allowing them to come up to the } \\
\text { whiteboard to reveal the answers, providing a "hands- } \\
\text { on" and learn by doing dimension to learning. }\end{array}$ \\
\hline $\begin{array}{l}\text { Technological Pedagogical and Content } \\
\text { Knowledge (TPACK) - knowledge of using the } \\
\text { Interactive Whiteboard in conjunction with specific } \\
\text { teaching methods for different types of subject } \\
\text { matter }\end{array}$ & $\begin{array}{l}\text { IWB word matching quiz activity } 2 \text { is designed to } \\
\text { teach students the concept of gradient for a straight- } \\
\text { line graph. Students will be learning by prior } \\
\text { knowledge, as they need to recall from their primary } \\
\text { school knowledge in order to participate this activity. }\end{array}$ \\
\hline
\end{tabular}

\section{Findings}

\section{Cycle 1}

Figure 1 shows an overview of the instructional process adopted during this cycle.

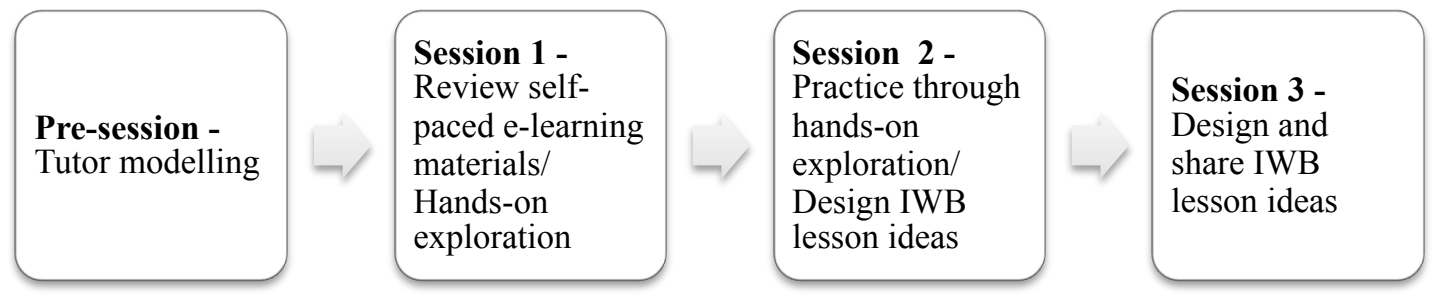

Figure 1. Instructional process used in Cycle 1.

This was conducted using the generic TEL process used during the course. Tutor modelling took place before the IWB lesson when the tutor used IWB functions such as the pen, eraser, highlighter, magnifier and spotlight to present the ICT lessons during the first five weeks of the semester. This strategy was deemed as appropriate for this IWB module because verification with the pre-service teachers at the beginning of the semester revealed that majority of them had not used the IWB before. During the faceto-face session in Session 1 the tutor reviewed the essential IWB features. This was followed by the preservice teachers accessing online materials to orientate themselves on the steps for using an IWB and controlling its applications such as to write, erase and save notes. The online materials also had information that guided them on how to use Microsoft applications with an interactive white board, and access to video-based resources that demonstrated how to construct interactive games and quizzes using 
Notebook, a software programme that supports the IWB hardware. It also provided pre-service teachers with links to download a trial version of the software for self-practice. Teachers took turns to explore the IWB hardware following which they completed their group reflections by commenting on how they thought the IWB can be used in the classroom, its benefits and limitations.

Session 2 was a face-to-face tutorial session where the pre-service teachers were given more opportunities to explore the IWB hardware. In an analysis of Singapore pre-service teachers' IWB learning behaviour, Divaharan and Koh (2010) found that group-based exploration provided pre-service teachers with peer support to overcome apprehensions about using this new technology. Therefore, group learning was also incorporated into this instructional cycle during which the pre-service teachers formed self-selected project teams comprising three to four members. During the lesson, they took turns to explore the IWB hardware with their project group members and shared with each other what they had learnt independently through the e-lesson. They took the opportunity to clarify doubts with their group mates as well as the tutor, thereby expanding their technical knowledge of the IWB. Each group also developed prototypes of IWB activities they felt could be incorporated into their final project. These prototypes were to be showcased to the tutor and their peers during Session 3 for critique and feedback. Session 3 extended the group-based learning approach of Session 2. Each project team shared about the IWB features that they had learnt, and showcased their prototypes of classroom applications. There was no explicit attempt to teach content in the IWB module since the pre-service teachers were also attending methods courses during the semester where content knowledge related to their curriculum subjects was being covered. Session 3, therefore, endeavoured to provide opportunities for pre-service teachers to relate their teaching subjects to the use of the IWB.

Cycle 1 findings

Figure 2 shows the results from content analysis of the teachers' reflections

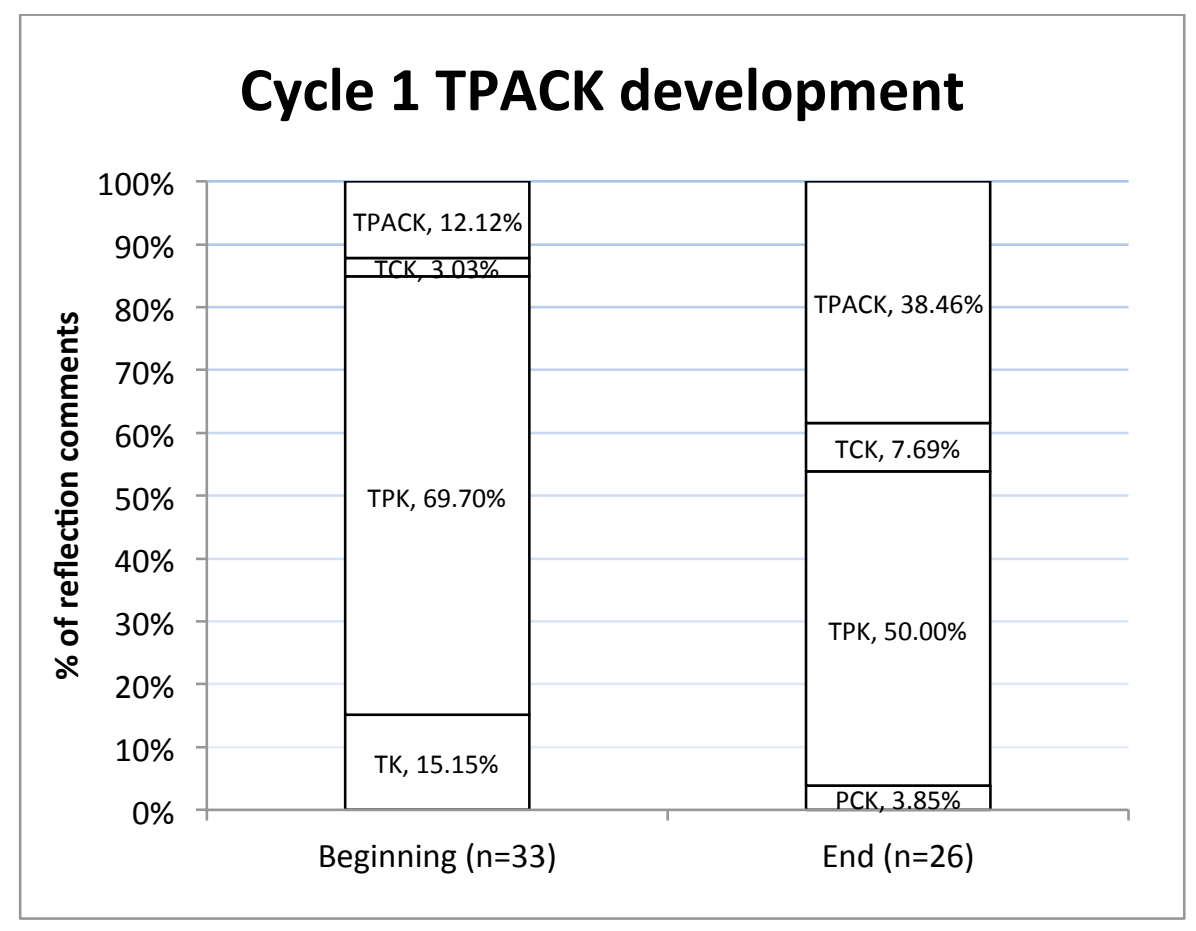

Figure 2. Teachers TPACK development during Cycle 1.

The pre-service teachers predominantly developed TPK through the pre-lesson tutor modelling, the online materials and their explorations with the IWB at the beginning of the module. Through observing the tutor model IWB use in her lessons and their hands-on exploration, they were able to appreciate the pedagogical uses of various IWB functions, for example, "Magic wand tool to magnify and focus on a 
particular word/phrase", "Making use of magnifying glass to unveil various locations on the map", and "Construct interactive activities for the students to take part in, so that they will be engaged in the lesson." Comments related to the acquisition of TK, such as, "We learnt how to zoom in, how to use the spot light and various functions of buttons and screen" were present but to a lesser extent as compared to TPK-type comments. This showed the pre-service teachers were already thinking about IWB use from the perspective of teachers rather than users at the beginning of the IWB lessons.

Analysis of pre-service teachers' reflections at the end of the semester revealed the predominance of TPKtype comments. However, compared to their early semester postings, their TPK-type comments evidenced more depth and a better articulation of the IWB's pedagogical function. For example:

For the first IWB activity, which is a brief review of the topic, questions will be asked of the students in certain slides. These slides have answers to the questions, but hidden by icons which can be dragged away, revealing the answers. This is a more interesting method compared to the traditional "writing answers on the board" method and may help engage the students to remember the information better.

Teachers' engagement in group-based design activities after the first lesson appeared to have had substantial impact in teachers' development of TPACK as there was a three-fold increase in the percentage of TPACK-type comments. The following is an example of a TPACK-type comment describing how teachers visualized the use of IWB within the classroom context.

Demonstrate factorisation of quadratic expressions through the use of algebraic tiles (algetiles) with the aid of IWB.

Design activities also appeared to have supported the teachers to make connections with the PCK that they learnt in their methods classes as these types of comments only emerged at the end of the semester:

Teachers can make the smooth transition from a teacher-centred approach to a studentcentred approach as the activities require class participation.

Lessons from Cycle 1

The findings from Cycle 1 showed that the instructional process had potential for fostering TPACK as TPACK-type comments were the second largest category after TPK. It was observed that the link between technology and teaching content was relatively weak, given that the percentage of comments attributable to TCK was low. Since the aim of the IWB TEL is to develop pre-service teachers' ability to design lesson activities for implementation in schools, there is a need for instructional processes to help them better formulate TPACK with respect to curriculum content. During Cycle 2, the researchers sought to examine the types of instructional methods that could help pre-service teachers make tighter connections between IWB use and instructional pedagogies within the context of their subject content, especially during the initial stages of their IWB learning experience. Using the precedence of teacher education studies where the modelling of ICT integration practices in methods courses have been proven successful (Beyerbach, Walsh, \& Vannatta, 2001; Brush, et al., 2003; Pope, Hare, \& Howard, 2005), the researchers sought to examine if modelling anchored upon teachers' teaching content would better enhance their TPACK after Session 1 which could result in better lesson ideas being developed by Session 3. Therefore, modifications were made to the instructional processes for the pre-lesson activities and Session 1 to enhance TPACK formation during Cycle 2. 


\section{Cycle 2}

Figure 3 depicts the instructional process used during Cycle 2.

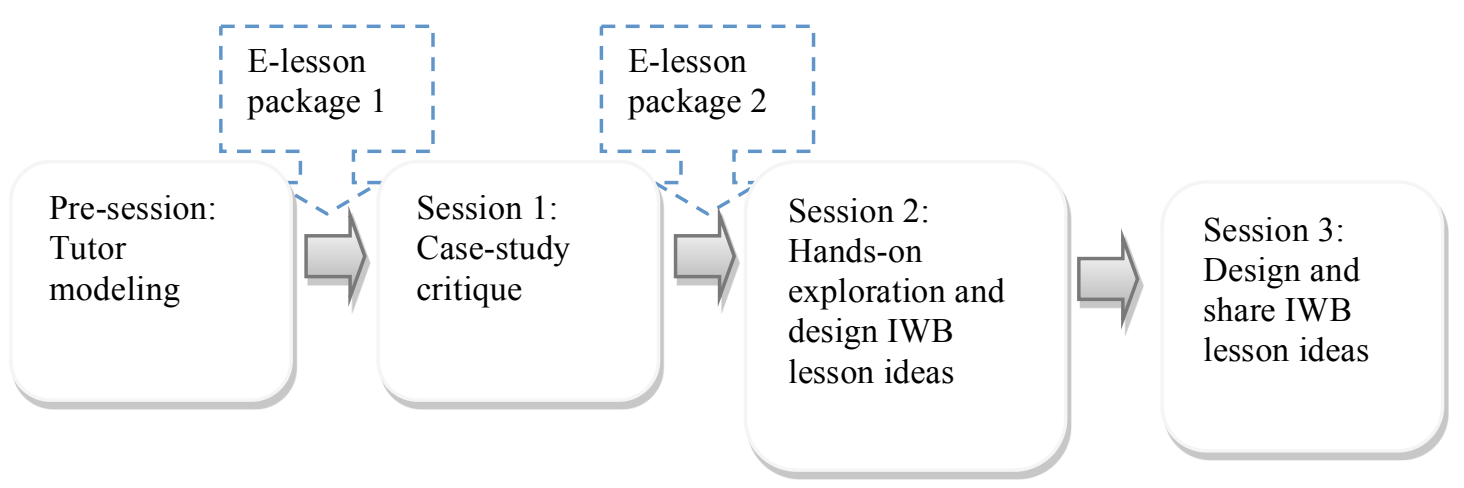

Figure 3. Instructional process used in Design Cycle 2.

Pre-session modelling by the tutor remained unchanged. The modification from Cycle 1 was that a week before Session 1, pre-service teachers were asked to complete a self-paced e-learning package. In this design cycle, the lesson package was enhanced with case studies of IWB use in Singapore schools. As part of their lesson preparation, each project group had to analyse a case study with respect to the following guiding questions:

- Why do you think the teacher decided to use the IWB as a tool in his lesson?

- In what manner did the teacher use the tool to promote interactivity?

- What were the features of IWB that the teacher used? How did the teacher use these features?

During session 1, the tutor conducted a class discussion of the pre-service teachers' analysis. This activity was designed to help them focus on the pedagogical approaches adopted by the teachers in the case studies. Following this, prior to session 2, the pre-service teachers were tasked to go through e-lesson package 2. In this package, they were provided with a range of IWB lesson packages from a range of curriculum subjects such as English, Mathematics, and History. The pre-service teachers chose packages that were relevant to their curriculum subjects and explored them. The intention of this activity was to enhance pre-service teachers' TPACK through the exploration of curriculum subject related IWB materials. For this activity, they were provided with guiding questions to help them consider how the lessons were developed, the types of activities that were designed to be interactive and how these ideas could be applied towards their own lesson design. Again, similar to Cycle 1, the pre-service teachers returned to class to share their findings and reflections as a group in the discussion forum by answering the same questions as in Cycle 1. At the end of the semester, they also provided a rationalization of their IWB lesson design as per Cycle 1 .

Analysis of Cycle 2 findings showed that TK and TPK remained predominant at the beginning of the semester. The addition of instructional activities requiring them to analyse school-based case studies and IWB lesson examples was envisioned to help teachers begin considering content integration at the beginning of Cycle 2. The percentage of TCK-type comments and TPACK-type comments did not differ greatly between Cycle 1 and Cycle 2. However, qualitative differences were observed in the TPACK-type comments as these were more elaborated and teachers were able to pinpoint specific lesson topics within a subject area:

Sentence arrangement! We decided that this can be used in our EL [English] lesson, as students will be able to re-arrange sentences according to plot features. 
Cycle 2 findings

Figure 4 shows the findings from the Cycle 2 reflections.

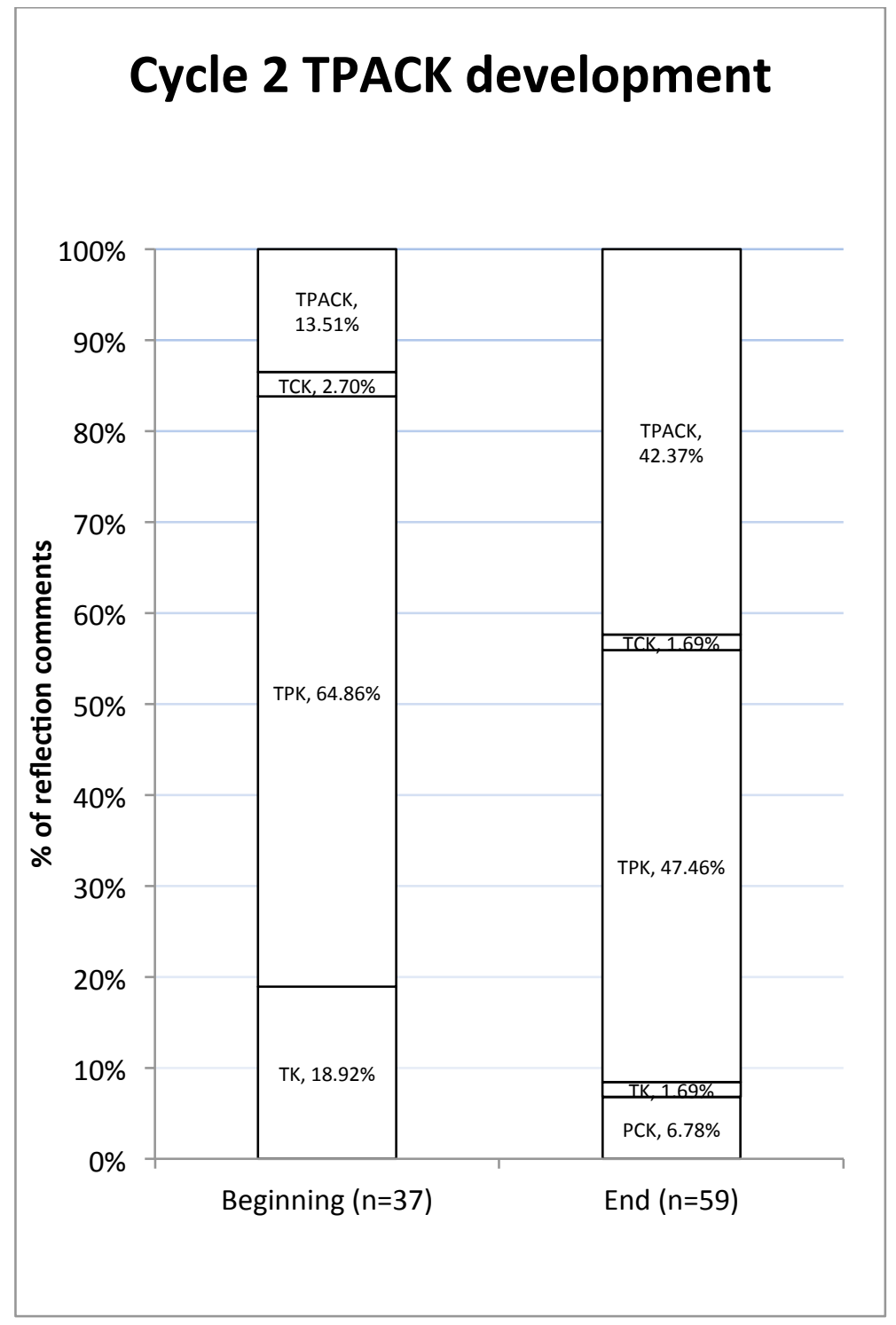

Figure 4. Teachers TPACK development during Cycle 2.

Teachers also made connections to knowledge of pedagogical methods taught in their methods courses in their TPACK comments, which was not as evident during Cycle 1. For example, in relation to the Word Scramble activity, a project group commented that,

The activity might also promote the spirit of collaborative and reciprocal learning when students with more extensive knowledge are able to advise their peers and help solve the puzzles in a team.

At the end of the semester, the percentage of TPK and TCK comments were lower than Cycle 1 but the percentage of TPACK comments was larger in Cycle 2 than in Cycle 1. This could indicate that the teachers were able to build upon the lesson ideas gathered through their e-lessons to better design their IWB lesson activities. As compared to Cycle 1, these comments were also more developed in pinpointing how IWB could support specific lesson topics. For example: 
A video depicting the Sri Lankan conflict will be showed [sic] to the students to create prior knowledge on this case study, following which, teacher will go through the timeline of the conflict to introduce students to this topic. The use of the IWB is especially useful for this as it allows teacher to present teaching materials in an attractive manner to engage the attention of these visual learners, and highlight and annotate on the timeline to make teaching more effective.

Teachers' reflections at the end of the semester also showed them considering the linkages between the IWB and non-IWB lesson activities, which were not evident during Cycle 1:

\begin{abstract}
After the presentation, the teacher will first make use of the IWB to model a sequencing task with a set of 'Cyberwellness' comic frames. Comics will particularly appeal to the visual learners, and will enable students to pick out narrative features from short sentences available in the conversational balloons. Following that, a worksheet containing a set of jumbled Garfield comic frames will be disseminated to every student. They will be given 5 minutes to rearrange the comic based on contextual clues. Some students will then be selected to name some of the comic frames on the IWB with the appropriate narrative stage. The element of competitiveness as motivation will be incorporated, so as to see who is able to complete the stage identification task in the shortest time possible.
\end{abstract}

There were also more instances of PCK-type comments, indicating that the teachers made stronger linkages with their knowledge from methods courses:

The activity might also promote the spirit of collaborative and reciprocal learning when students with more extensive knowledge are able to advise their peers and help solve the puzzles in a team.

Lessons from Cycle 2

From Mishra and Koehler's (2006) conception, TCK is viewed as an intermediate form of knowledge that preceded TPACK. The lesson exemplars were added to enhance TCK, which dealt with the general ways of representing lesson content with technology tools (Cox \& Graham, 2009). However, contrary to expectation, these lesson exemplars seemed to function as more effective models of TPACK, which is the knowledge of implementing specific technology-integrated lesson activities for specific lesson topics within a subject area. Nevertheless, PK and CK did not emerge in this study. It could be that the lesson exemplars allowed teachers to immediately connect TK with PCK, thereby omitting the need to start from $\mathrm{PK}$ and CK. This is an area that is not fully understood from this study, which warrants further analysis.

\title{
Instructional strategies and TPACK formation
}

TPACK is a form of teacher expertise that is derived from the multiple knowledge bases of TK, PK, and CK. Mishra and Koehler (2006) emphasized that teachers' technology integration expertise emerged from the connections between these sources of knowledge. Therefore, PCK, TPK, TCK, and TPACK are the important sources of knowledge to develop among the seven TPACK constructs. When analysing the epistemological nature of PCK, Gess-Newsome (1999) proposed that it could be viewed as integrative or transformative. The integrative view proposes that PCK is a simple combination of PK and CK during teaching where each element can be isolated whereas the transformative view proposes PCK to be a unique amalgamation of PK and CK into a new form of knowledge.

The epistemological nature of PCK is noteworthy for teacher educators as they are thinking about the methods for developing teaching expertise among teachers. An integrative view suggests that fostering $\mathrm{PK}$ and $\mathrm{CK}$ is sufficient for growing teachers' PCK. It is long recognized that teaching teachers technology skills is not equivalent to teaching them about technology integration (Moursund \& Bielefeldt, 1999; Strudler \& Wetzel, 1999). Rather than starting with the technological functions of the IWB, preservice teachers in this study were taught the IWB technological functions at the beginning of both cycles through tutor modelling, which developed their TPK. When they were asked to critique IWB lesson examples in Cycle 2, it did not increase the magnitude of comments made on TPACK but qualitatively, their TPACK considerations were more sophisticated. Like other studies (Angeli \& Valanides, 2005, 2009), this study found that TPACK should be approached as a unique body of knowledge to be acquired 
by teachers. In accordance with the spirit of design-based research which is to support the long-term aim of building theory (Lesh et al., 2008), we explicate our preliminary understandings of the relationship among strategies adopted for IWB instruction as well as teachers' TPACK in the following sections.

The two implementation cycles suggest that multiple instructional strategies need to be adopted in a TPACK-fostering ICT instructional process because each addressed different aspects of teachers' TPACK development (See Figure 5).

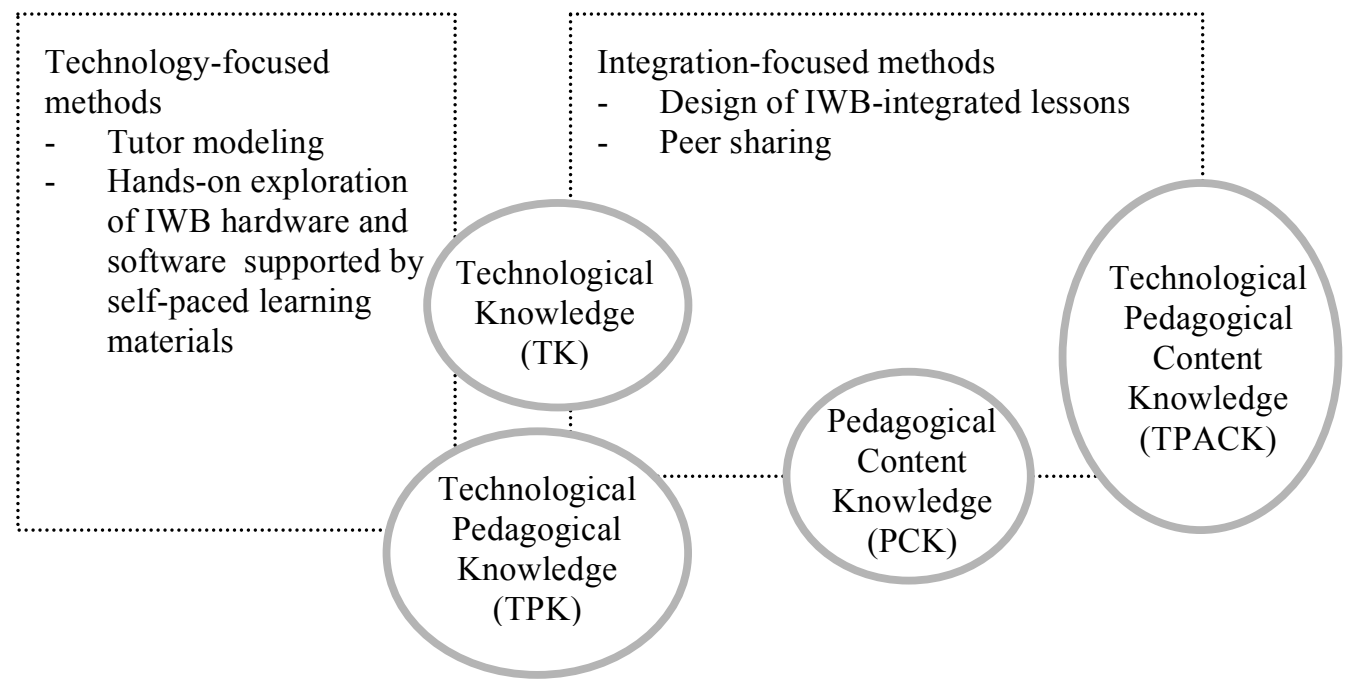

Figure 5. ICT instructional strategies and teachers' TPACK formation.

The results from the beginning stages of the two cycles showed that tutor modelling and hands-on exploration of ICT tools can be viewed as technology-focused methods that were more advantageous for fostering knowledge related to the technology, i.e., TK and TPK. Research studies have shown that effective use of computers is dependent on the teachers' ICT skills as well as their intention of ICT use (Vanderlinde, Braak, \& Hermans, 2009; Venezky, 2004). Faculty modelling has also been found useful in developing pre-service teachers' confidence to use ICT tools (Beyerbach, et al., 2001; Brush, et al., 2003; Pope, et al., 2005), which Niess (2007) emphasized to be an important starting point for teachers' TPACK development. Such vicarious experiences prepared the pre-service teachers to learn the IWB independently through a self-paced e-learning tutorial during the initial stages of the IWB model.

The second group of methods were termed as integration-focused methods, that is, the use of group-based design experiences to help teachers integrate technology, pedagogy, and content. Consistently across both cycles, these methods predominantly supported the teachers to develop their conceptions of TPACK. These design activities could have also provided a contextual basis for evoking teachers' PCK, which was largely absent during the early stages of the module during both cycles. Research studies have suggested that teacher learning occurs as they share with each other (Flanagan \& Jacobsen, 2003; Prain \& Hand, 2003), which was supported in this study. It should be noted that technology-focused methods were necessary to provide teachers with a foundation to undertake these design activities.

The analysis of content-based examples through cases and IWB lesson packages at the beginning stages of Cycle 2 did not appear to have helped teachers to better foster their TCK but could have deepened their TPACK conceptions by the end of Session 3. One reason is that thinking and reflecting about ICT practices may be more influential on TPACK than on TCK. The lesson examples, creation of the IWB integrated lesson components by the groups in their content areas and sharing them with their classmates provided the teachers with content examples that were evoked during the actual design of an ICT lesson. The "doing" of ICT integration allowed teachers to apply these resources towards lesson design, thereby developing TPACK. The findings of Mishra, Koehler, and Yahya (2007) appear to support this thesis. Another explanation could be that TPK rather than TCK was more influential for pre-service teachers' TPACK formation. Statistical modelling of in-service teachers' TPACK conceptions show TCK to be slightly more influential than TPK, possibly because they are more experienced with school-based 
curriculum demands (Koh, Chai, \& Tsai, 2012). Nevertheless, in a factor analysis of pre-service teachers' TPACK conceptions, TCK did not emerge as a factor (Chai, Koh, Tsai, \& Tan, 2011). While Chai, Koh, and Tsai (2011) were able to extract TCK as a specific factor by revising the TPACK survey used by Chai, Koh, Tsai, and Tan (2011), they did not perform statistical modelling to further examine the effects of TCK on TPACK. Therefore, the findings of this study show that the specific effects of TCK on TPACK as well as the instructional methods for fostering TCK still need to be further examined.

\section{Limitations and future developments}

This study examines how the instructional strategies employed in an IWB instructional process fostered teachers' TPACK development. The generalizability of these findings to lesson modules focusing on other ICT tools or teacher education ICT courses need to be further examined. The IWB was only one of the ICT tools that the teachers learnt during the semester. It is unclear how these other learning experiences may have influenced their IWB learning behaviour, which is another limitation of this study. There is a need to examine the applicability of the instructional process to ICT courses where several ICT tools may be covered.

When applying this instructional process in future cycles, several aspects can be further analysed to improve the process. Firstly, does engagement in more design activities better foster teachers' TPACK? This study shows design activities being important for teachers' TPACK formation. Angeli and Valanides (2009) found that multiple design cycles were useful for enhancing teachers' TPACK. In the next implementation cycle, the instructional process could be modified to incorporate smaller scale lesson design activities into the early stages of the module. These design activities could be used as scaffolds to help teachers develop their IWB lesson. The effects of these design experiences on teachers' TPACK formation could be studied.

Secondly, the contributions of TPK and TCK to teachers' TPACK development need to be further examined. To date, TPACK remains a theoretical model needing to be validated (Koh, Chai, \& Tsai, 2010). Statistical modelling of the relationships between TPACK constructs found evidence of TK, PK, and CK being significant predictors of TPACK but the contributions of TPK and TCK still need to be examined. Since TPACK is related to teachers' knowledge about ICT integration for specific lesson activities and topics, it appears that design activities should be given more emphasis than the activities such as faculty modelling, hands-on exploration of ICT tools, and lesson critique activities. Yet, when examining teachers' TPACK formation with respect to unfamiliar ICT tools, Niess (2007) and Koh and Divaharan (2011) found that they needed to first understand the technical functions of the tools as users before they were better able to consider its pedagogical uses. Activities such as faculty modelling could better support these initial stages of teachers' TPACK formation. With the incorporation of more design activities into the design cycle, it is important to examine if constructs such as TPK still take precedence over TPACK during the initial stages of the design cycle. If yes, this would imply the need to pay attention to instructional strategies that develop these precedents of TPACK.

Thirdly, instructional strategies other than design projects could be incorporated to support more extensive development of TPACK in the latter stages of the design cycle. Cavin (2008) proposed that teacher engaged in microteaching activities to be a method of fostering their TPACK. Group sharing in the latter parts of the design cycle could be modified into sessions for microteaching where each project group teach their ICT segment to the class. The efficacy of this strategy for enhancing the prevalence of TPACK in teachers' reflection comments at the end of the semester should be examined.

Finally, by purposively selecting secondary school teachers from the PGDE programme who were taught by the same tutor, the researchers attempted to maintain consistency in the participant profile. Nevertheless, the use of a design-based approach led to both cycles being conducted in a naturalistic context. Therefore, the researchers were unable to re-create the actual setting experienced by Cycle 1 preservice teachers for the Cycle 2 teachers. In addition, it should be noted that the pre-service teachers involved in this study are from a particular program. It will be myopic to assume or to claim that the instructional approach can be adopted in its entirety in other contexts. Therefore, the process still needs to be further validated. 


\section{Conclusion}

This study exemplifies the development and refinement of a TPACK-fostering ICT instructional process. The results suggest that teachers' TPACK could be enhanced through the use of multiple types of instructional strategies. Nevertheless, some strategies are better targeted at TPACK development than others. The instructional process outlined in this study need to be further examined for its applicability to the teaching of ICT tools other than the IWB, and with other target groups such as in-service teachers. This can contribute to the development of TPACK-fostering instructional processes that bridges the theory-application nexus of the TPACK framework developed by Mishra and Koehler (2006).

\section{References}

AACTE. (2008). Handbook of technological pedagogical content knowledge (TPCK) for educators. Oxon: Routledge.

Angeli, C., \& Valanides, N. (2005). Preservice elementary teachers as inforamtion and communication technology designers: An instructional systems design model based on an expanded view of pedagogical content knowledge. Journal of Computer Assisted Learning, 21, 292-302.

Angeli, C., \& Valanides, N. (2009). Epistemological and methodological issues for the conceptualization, development, and assessment of ICT-TPCK: Advances in technological pedagogical content knowledge (TPCK). Computers \& Education, 52(1), 154-168.

Beyerbach, B., Walsh, C., \& Vannatta, R. (2001). From teaching technology to using technology to enhance student learning: Preservice teachers' changing perceptions of technology infusion. Journal of Technology and Teacher Education, 9(1), 105-127.

Brown, A. L. (1992). Design experiments: Theoretical and methodological challenges in creating complex interventions in classroom settings. The Journal of The Learning Sciences, 2(2), 141178.

Brush, T., Glazewski, K., Rutowski, K., Berg, K., Stromfors, C., Hernandez Van-Nest, M., . . Sutton, J. (2003). Integrating technology in a field-based teacher training program: The PT3@ ASU project. Educational Technology Research and Development, 51(1), 57-72.

Brush, T., \& Saye, J. W. (2009). Strategies for preparing preservice Social Studies teachers to integrate technology effectively: Models and practices. Contemporary Issues in Technology and Teacher Education, 9(1), 46-59.

Cavin, R. (2008). Developing technological pedagogical content knowledge in preservice teachers through microteaching lesson study. Technology and Teacher Education Annual, 19(8), 5214.

Chai, C. S., Koh, J. H. L., \& Tsai, C. C. (2011). Exploring the factor structure of the constructs of technological, pedagogical, content knowledge (TPACK). The Asia-Pacific Education Researcher, 20(3), 595-603.

Chai, C. S., Koh, J. H. L., Tsai, C. C., \& Tan, L. W. L. (2011). Modeling primary school pre-service teachers' Technological Pedagogical Content Knowledge (TPACK) for meaningful learning with information and communication technology (ICT). Computers \& Education, 57(1), 1184-1193. doi: 10.1016/j.compedu.2011.01.007

Cobb, P., diSessa, A., Lehrer, R., \& Schauble, L. (2003). Design experiments in educational research. Educational Researcher, 32(1), 9-13.

Cox, S., \& Graham, C. R. (2009). Diagramming TPACK in practice: Using an elaborated model of the TPACK framework to analyze and depict teacher knowledge. TechTrends, 53(5), 60-69.

Divaharan, S., \& Koh, J. H. L. (2010). Learning as students to become better teachers: Pre-service teachers' IWB learning experience. Australasian Journal of Educational Technology, 26(4), 553-570. 
Flanagan, L., \& Jacobsen, M. (2003). Technology leadership for the twenty-first century principal. Journal of Educational Administration, 41(2), 124-142.

Gess-Newsome, J. (Ed.). (1999). Pedagogical content knowledge: An introduction and orientation. Netherlands: Springer.

Grandgenett, N. F. (2008). Perhaps a matter of imagination: TPCK in mathematics educaton. In AACTE committee on innovation and technology (Eds.), Handbook of technological pedagogical content knowledge (TPCK) for educators (pp. 145-166). New York, NY: Routledge.

Handler, M. G. (1993). Preparing new teachers to use computer technology: Perceptions and suggestions for teacher educators. Computers and Education, 20(2), 147-156.

Hughes, J. E., \& Scharber, C. M. (2008). Leveraging the development of English TPCK within the deictic nature of literacy. In AACTE committee on innovation and technology (Eds.), Handbook of technological pedagogical content knowledge (TPCK) for educators (pp. 87-106). New York: NY: Routledge.

Koehler, M. J., \& Mishra, P. (2005a). Teachers learning technology by design. Journal of computing in teacher education, 21(3), 94-102.

Koehler, M. J., \& Mishra, P. (2005b). What happens when teachers design educational technology? The development of technological pedagogical content knowledge. Journal of Educational Computing Research, 32(2), 131-152.

Koehler, M. J., Mishra, P., \& Yahya, K. (2007). Tracing the development of teacher knowledge in a design seminar: Integrating content, pedagogy and technology. Computers \& Education, 49(3), 740762.

Koh, J. H. L., Chai, C. S., \& Tsai, C. C. (2010). Examining the technology pedagogical content knowledge of Singapore pre-service teachers with a large-scale survey. Journal of Computer Assisted Learning, 26(6), 563-573.

Koh, J. H. L., Chai, C. S., \& Tsai, C. C. (2012). Examining practicing teachers' perceptions of technological pedagogical content knowledge (TPACK) pathways: A structural equation modeling approach. Instructional Science. doi: 10.1007/s11251-012-9249-y

Koh, J. H. L., \& Divaharan, S. (2011). Developing pre-service teachers' technology integration expertise through the TPACK-developing instructional model Journal of Educational Computing Research, 44(1), 35-58.

Lesh, R., Kelly, A., \& Yoon, C. (2008). Multi-tier design experiments in mathematics, science, and technology education. In A. E. Kelly, J. Y. Baek, \& R. A. Lesh (Eds.), Handbook of design research methods in education: Innovations in science, technology, engineering, and mathematics (pp. 131148). New York: Routledge.

McCrory, R. (2008). Science, technology, and teaching: The topic-specific challenges of TPCK in science. In AACTE committee on innovation and technology (Eds.), Handbook of Technological Pedagogical Content Knowledge (TPCK) for Educators (pp. 193-206). New York and London: Routledge.

Mishra, P., \& Koehler, M. J. (2006). Technological Pedagogical Content Knowledge: A Framework for Teacher Knowledge. Teachers College Record, 108(6), 1017-1054.

Moursund, D., \& Bielefeldt, T. (1999). Will new teachers be prepared to teach in a digital age? A national survey on information technology in teacher education. Santa Monica, CA: Milken Family Foundation.

Niess, M. L. (2007). Developing teacher's TPCK for teaching mathematics with spreadsheets. Technology and Teacher Education Annual, 18(4), 2238-2245. 
Özgün-Koca, S. A., Meagher, M., \& Edwards, M. T. (2009/2010). Preservice teachers' emerging TPACK in a technology-rich methods class. The Mathematics Educator, 19(2), 10-20.

Pope, M., Hare, D., \& Howard, E. (2005). Technology integration: Closing the gap between what preservice teachers are taught to do and what they can do. Journal of Technology and Teacher Education, 10(2), 191-203.

Prain, V., \& Hand, B. (2003). Using new technologies for learning: A case study of a whole-school approach. Journal of Research on Technology in Education, 35(4), 441-458.

Shulman, L. S. (1986). Those who understand: Knowledge growth in teaching. Educational Researcher, 15(2), 4-14. doi:10.3102/0013189x015002004

So, H. J., \& Kim, B. (2009). Learning about problem based learning: Student teachers integrating technology, pedagogy and content knowledge. Australasian Journal of Educational Technology, 25(1), 101-116.

Strudler, N. B., \& Wetzel, K. (1999). Lessons from exemplary colleges of education: factors affecting technology integration in preservice programs. Educational Technology Research and Development, 47(4), 63-81.

Vanderlinde, R., Braak, J. V., \& Hermans, R. (2009). Educational technology on a turning point: curriculum implementation in Flanders and challenges for schools. Educational Technology and Research Development, 57, 573-584.

Venezky, R. L. (2004). Technology in the classroom: Steps toward a new vision. Education, Communication and Information, 4(1), 3-21.

Corresponding author: Joyce Hwee Ling Koh, joyce.koh@nie.edu.sg

Australasian Journal of Educational Technology (C) 2013.

Please cite as: Koh, J. H. L., \& Divaharan, S. (2013) Towards a technological pedagogical content knowledge-fostering information and communication technology instructional process for teachers: Lessons from the implementation of interactive whiteboard instruction. Australasian Journal of Educational Technology. 29(2), 233-247. 